\title{
Interrelationship between insulin resistance and impaired immune phenotype of circulating endothelial-derived microparticles in none-diabetic patients with chronic heart failure
}

\author{
Alexander E Berezin ${ }^{1 *}$, Alexander A Kremzer ${ }^{2}$, Tatyana A Samura ${ }^{2}$, Yulia V Martovitskaya ${ }^{3}$ and Tatyana A Berezina ${ }^{4}$ \\ ${ }^{1}$ Internal Medicine Department, State Medical University, Zaporozhye, Ukraine \\ ${ }^{2}$ Clinical Pharmacology Department, State Medical University, Zaporozhye, Ukraine \\ ${ }^{3}$ Pathology Department, State Medical University, Zaporozhye, Ukraine \\ ${ }^{4}$ Private Medical Center "Vita-Center", Zaporozhye, Ukraine
}

\begin{abstract}
Background: The causality role of different immune phenotype in IR developing among Chronic Heart Failure (CHF) subjects has not determined obviously. The aim of the study was to assess relationship between IR and immune phenotype of circulating endothelial-derived microparticles (EMPs) in patients with CHF.

Methods: The study retrospectively involved $300 \mathrm{CHF}$ patients aged 48 to 62 years who were undergone multispiral computed tomography angiography or coronary angiography. All the patients have given written informed consent for participation in the study. Biomarkers were measured at baseline of the study.

Results: These were not significant differences between both cohort patients in EMPs labeled as CD144+/CD31+, CD144+/annexin V+, and CD62E+ microparticles. Higher concentrations of CD144+/CD31+/annexin V+ EMPs and CD31+/annexin V+ EMPs were found in IR subjects when compared with none IR patients. Using multivariate logistic regression analyses, we found that HOMA-IR (OR=1.14, 95\% CI=1.08-1.21, $\mathrm{P}=0.001)$, NT-proBNP $(\mathrm{OR}=1.07,95 \% \mathrm{CI}=1.04-1.10$, $\mathrm{P}=0.001)$, hs-CRP $(\mathrm{OR}=1.04,95 \% \mathrm{CI}=1.02-1.07, \mathrm{P}=0.001)$, and NYHA class $(\mathrm{OR}=1.03,95 \% \mathrm{CI}=1.01-1.05, \mathrm{P}=0.001)$ were predictors for increased $\mathrm{CD} 31+/$ annexin V+ EMPs. Therefore, HOMA-IR ( $\mathrm{OR}=1.10,95 \% \mathrm{CI}=1.05-1.17, \mathrm{P}=0.001)$, NT-proBNP ( $\mathrm{OR}=1.08,95 \% \mathrm{CI}=1.04-1.12, \mathrm{P}=0.001)$, and NYHA class $(\mathrm{OR}=1.05,95 \% \mathrm{CI}=1.02-1.09, \mathrm{P}=0.001)$ significantly predicted elevation of CD144+/CD31+/annexin V+ EMPs. Using C-statistics for Models with HOMA-IR, NYHA class, and circulating biomarkers (hs-CRP, NT-proBNP) as Continuous Variables we found that adding of combination of these biomarkers to the based model constructed with HOMA-IR did not improve the relative IDI for increased CD144+/CD31+/annexin V+ and CD31+/annexin V+ microparticles. When we used other model constructed on entering variables, IDI avoids to be improved for increased CD144+/CD31+/annexin V+ and CD31+/annexin V+ microparticles.

Conclusion: We found that IR remains statistically significant predictor for increased apoptotic-derived EMPs labelled as CD144+/CD31+/annexin V+ and CD31+/ annexin V+ EMPs in none-diabetic patients with CHF patients and that these findings reflect exiting impaired phenotype of circulating EMPs in this patient population.
\end{abstract}

\begin{abstract}
Abbreviations: AUC: area under curve BMI: body mass index; BMP: brain natriuretic peptide; $\mathrm{CI}$-confidence interval; CHF: chronic heart failure; EMPs: endothelial-derived microparticles; IR: insulin resistance, hs-CRP: high sensitive C-reactive protein; GFR: glomerular filtration rate; LVEF: left ventricular ejection fraction; NYHA: New York Heart Association; OR: odds ratio NRI: net reclassification improvement
\end{abstract}

\section{Introduction}

Chronic Heart Failure (CHF) is an increasingly common condition that is characterized raised prevalence worldwide and associated with cardiovascular morbidity and mortality [1]. The results of few population-based and epidemiological investigations show that multiple risk factors and various metabolic comorbidities presented in CHF patients are able to affect nature evolution of cardiac failure [2-5]. Therefore, exiting differences in the prevalence of risk factors and comorbidities in patients with CHF may not completely explain sufficient distinguishes in survival in CHF patient population [6-8]. Recently, increasing attention has been paid to Insulin Resistance (IR) as a distinct cause of cardiac dysfunction and CHF in diabetic and nondiabetic patients $[9,10]$.IRmediates excessive or inadequate proliferation of the extracellular matrix accelerates apoptosis via increased oxidative stress, neurohumoral and inflammatory activation that negatively effect on cardiac remodeling, vasomotion, and endothelial function

Correspondence to: Alexander E. Berezin, Professor, MD, PhD, Internal Medicine Department, State Medical University, 26, Mayakovsky Av., Zaporozhye, Postcode 69035, Ukraine, Tel: +38 061 2894585; Fax: +38 0612894585; E-mail: dr_berezin@mail.ru

Key words: chronic heart failure, insulin resistance, endothelial-derived microparticles, immune phenotype

Received: January 15, 2015; Accepted: March 15, 2015; Published: March 22, 2015 
Berezin AE (2015) Interrelationship between insulin resistance and impaired immune phenotype of circulating endothelial-derived microparticles in none-diabetic patients with chronic heart failure

[11-14]. Despite IR is considered a main component of metabolic syndrome and type two diabetes mellitus (T2DM), individuals with CHF may present IR prior to other dysmetabolic conditions $[15,16]$. However, the causality association of IR with none T2DM CHF patient $\mathrm{s}$ is unclear and the underlying mechanisms of advance CHF affected IR have not been fully elucidated.

Recent studies have shown the role of circulating endothelialderived microparticles (EMPs) in nature evolution of CHF with possibility predictive value [17-20]. Extracellular EMPs are defined as microvesicles with sizes ranging between 50 and $1000 \mathrm{~nm}$ released from plasma membrane of endothelial cells due to apoptosis or cell activation by specific (cytokine stimulation, mononuclear cooperation, coagulation, etc) and non-specific (shear stress) stimuli [21]. Apoptotic-derived or activated endothelial cell-derived EMPs are capable of transferring biological information, regulating peptides, hormones, proteins, lipid components without direct cell-to-cell contact to maintain cell homeostasis $[22,23]$. Interestingly, circulating EMPs derived from activated endothelial cells did not contain nuclear components and they have also been shown to have pro-angiogenic and cardio-protective properties [24,25]. In opposite, apoptoticderived EMPs consist immune mediators, which are able to generating powerful signaling by the simultaneous receptor interaction and they are discussed a marker of endothelial cell injury and vascular aging $[26,27]$.

However, the role of different immune phenotype in developing IR among CHF patients has not determined obviously. The aim of the study was to assess relationship between IR and immune phenotype of circulating EMPs in patients with CHF.

\section{Methods}

The study retrospectively involved 300 CHF patients aged 48 to 62 years who were undergone multispiral computed tomography angiography or coronary angiography in our centers between February 2011 and November 2013. Enrolled subjects presented atherosclerotic stenosis $>50 \%$ of at least one coronary artery or they reported previously defined myocardial infarction. We excluded patients with acute infections; active inflammation; pulmonary edema; tachyarrhythmia; valvular heart disease; thyrotoxicosis; ischemic stroke; intracranial hemorrhage; surgery; trauma, autoimmune disease, malignancy, and acute coronary syndrome within 3 months prior to the study entry.All participants gave full written informed written consent.

\section{Methods for visualization of coronary arteries}

Contrast-enhanced multispiral computed tomography angiography has been performed for all the patients with dysmetabolic disorder prior to their inclusion in the study on Optima CT660 scanner (GE Healthcare, USA) using non-ionic contrast Omnipaque (Amersham Health, Ireland) [28].

\section{Echocardiography and Doppler examination}

Transthoracic echocardiography and Tissue Doppler Imaging was performed according to a conventional procedure on ACUSON ultrasound system (SIEMENS, Germany) using 2.5-5 $\mathrm{MHz}$ phased probe. The left ventricular ejection fraction (LVEF) was measured by modified Simpson's method [29]. Tissue Doppler echocardiography was carried out in 4-, 3-, and 2-chamber views in each of 16 segments of the left ventricle and in 4 spots of the mitral annulus [30].

2.3 Insulin resistance assessment
Insulin resistance was assessed by the homeostasis model assessment for insulin resistance (HOMA-IR) [31] using the following formula:

HOMA-IR $(\mathrm{mmol} / \mathrm{L} \times \mu \mathrm{U} / \mathrm{mL})=$ fasting glucose $(\mathrm{mmol} / \mathrm{L}) \times$ fasting insulin $(\mu \mathrm{U} / \mathrm{mL}) / 22.5$

Insulin resistance was defined when estimated HOMA-IR value was over $2.77 \mathrm{mmol} / \mathrm{L} \times \mu \mathrm{U} / \mathrm{mL}$.

\section{Calculation of glomerular filtration rate}

Glomerular filtration rate (GFR) was calculated with CKD-EPI formula [32].

\section{Blood sampling}

Blood samples were drawn in the morning (at 7-8 a.m.) into cooled silicone test tubes wherein $2 \mathrm{~mL}$ of $5 \%$ Trilon B solution were added; then they were centrifuged upon permanent cooling at 6,000 rpm for 3 minutes. Then, plasma was refrigerated immediately to be stored at a temperature not higher than $-35^{\circ} \mathrm{C}$. N-terminal probrain natriuretic peptide (NT-pro-BNP) level was measured by immunoelectrochemoluminescent assay using sets by the Elecsys proBNP kit on Elecsys 1010 analyzer (Roche, Mannheim, Germany). High-sensitivity C-RP levels were measured by immunoturbidimetric assay on "AU640 Analyzer" (Olympus Diagnostic Systems Group, Japan). Concentrations of total cholesterol (TC) and cholesterol of high-density lipoproteins (HDLP) were measured by enzymatic method. The concentration of cholesterol of low-density lipoproteins (LDL-C) was calculated according to the Friedewald formula (1972) [33].

\section{Identifying immune phenotype of EMPs}

Circulating EMPs were isolated from $5 \mathrm{ml}$ of venous citrated blood drawn from the fistula-free arm. Platelet-free plasma (PFP) was separated from whole blood and then was centrifugated at 20,500 $\times$ rpm for $30 \mathrm{~min}$. EMPs pellets were washed with DMEM (supplemented with $10 \mu \mathrm{g} / \mathrm{ml}$ polymyxin B, $100 \mathrm{UI}$ of streptomycin, and $100 \mathrm{U} / \mathrm{ml}$ penicillin) and centrifuged again (20,500 rpm for $30 \mathrm{~min})$. The obtained supernatant was extracted, and pellets were re-suspended into the remaining $200 \mu \mathrm{l}$ of supernatant. PFP, EMPs, pellet, and supernatant were diluted five-, 10-, and five-fold in PBS, respectively [34].

Endothelial-derived apoptotic and activated microparticles were phenotyped by flow cytometry by phycoerythrin (PE)-conjugated monoclonal antibody against CD31 (Platelet Endothelial Cell Adhesion Molecule [PECAM]-1), CD144 (Vascular Endothelial [VE]-cadherin), CD62E (E-selectin), and annexin V (BD Biosciences, USA) followed by incubation with fluorescein isothiocyanate (FITC)-conjugated annexin V (BD Biosciences, USA) per HD-FACS (High-Definition Fluorescence Activated Cell Sorter) methodology independently after supernatant diluted without freeze [35]. The samples were incubated in the dark for $15 \mathrm{~min}$ at room temperature according to the manufacturer's instructions. For each sample, 500 thousand events have been analyzed. EMPs gate was defined by size, using 0.8 and $1.0 \mathrm{~mm}$ beads (Sigma, St Louis, MO, USA). CD31+/annexin V+ and CD144+/CD31+/annexin V+ microparticles were defined as apoptotic EMPs, EMPs positively labeled for CD62E+ were determined as EMPs produced due to activation of endothelial cells [36].

\section{Statistical analysis}

Statistical analysis of the results obtained was carried out in SPSS 
Berezin AE (2015) Interrelationship between insulin resistance and impaired immune phenotype of circulating endothelial-derived microparticles in none-diabetic patients with chronic heart failure

system for Windows, Version 20 (SPSS Inc, Chicago, IL, USA). The data were presented as mean $(\mathrm{M})$ and standard deviation $( \pm \mathrm{SD})$ or a $95 \%$ confidence interval $(95 \% \mathrm{CI})$; the median $(\mathrm{Me})$ and the $25 \%-75 \%$ interquartile range (IQR). The hypothesis of normal distribution of the parameters analyzed was checked by means of Shapiro-Wilk test and Kolmogorov-Smirnov test. To compare the main parameters of patients' groups (subject to the type of distribution of the parameters analyzed), one-tailed Student $t$-test or Shapiro-Wilk U-test were used. The two-tailed version of Wilcoxon test was used for paired comparison of parameter values inside the group. To compare categorical variables between groups, $\mathrm{Chi}^{2}$ test $\left(\chi^{2}\right)$ and Fisher $\mathrm{F}$ exact test were used. The factors, which could be associated potentially with circulating EMPs, were determined by means of univariate analysis of variance (ANOVA). Finally, we used logistic regression to calculate the odds ratio (OR) and a 95\% CI for all the independent predictors of elevated circulating EMPs. The calculated difference of $\mathrm{P}<0.05$ was considered statistically significant and all tests are reported two-tailed.

\section{Results}

General characteristic of the patients included in the study is reported in Table 1. Three hundred none diabetes patients with CHF $(62.0 \%$ males $)$ with mean age for $59.50 \pm 7.30$ years were divided into two cohorts depended on calculated value of HOMA-IR. Subjects with HOMA-IR $>2.77 \mathrm{mmol} / \mathrm{L} \times \mu \mathrm{U} / \mathrm{mL}$ were defined as patients with IR $(\mathrm{n}=171)$. However, patients with HOMA-IR $<2.77 \mathrm{mmol} / \mathrm{L}$ $\times \mu \mathrm{U} / \mathrm{mL}$ were classified as none IR subjects $(n=129)$. The patients of both cohorts were age- and sex-matched. Cardiovascular risk factors (adherence to smoking, hypertension, dyslipidemia) were found in similar proportion in both cohort patients. There was no significant difference in GFR, creatinine, serum total cholesterol, high-density lipoprotein cholesterol between both patient cohorts. However, obesity was appeared more frequent in IR patients. Therefore, IR patients had a significantly higher BMI, HbAlc, fasting blood glucose, insulin, hsCRP, serum low-density lipoprotein cholesterol, NT-pro-BNP. Systolic and diastolic blood pressures, heart rate in both patient cohorts were comparable.

Concomitant medications in CHF patients included in the study are summarized in Table 2. Proportion of the patients included in both cohorts who were treated with ACE inhibitors or ARBs, mineralocorticoid receptor antagonists, loop diuretics, acetylsalicylic acid, and statins were similar. Beta-blockers and $\mathrm{i} / \mathrm{f}$ blocker ivabradine were prescribed statistically much more in CHF subjects with IR when compared with none IR subjects $(\mathrm{P}=0.016)$. Other antiplatelet drugs were used more much frequently in none IR subjects (9.3\%) than in IR patients $(5.8 \% ; \mathrm{P}=0.046)$.

Immune phenotypes of EMPs in CHF patients were presented in Table 3. These were not significant differences between both cohort patients in EMPs labeled as CD144+/CD31+, CD144+/annexin V+, and $\mathrm{CD} 62 \mathrm{E}+$ microparticles. In opposite, higher concentrations of CD144+/CD31+/annexin V+ EMPs and CD31+/annexin V+ EMPs were found in IR subjects when compared with none IR patients.

The univariate linear regression shown that numerous of CD144+/ $\mathrm{CD} 31+$ /annexin $\mathrm{V}+$ EMPs was associated with NYHA class $(\mathrm{r}=0.59$; $\mathrm{P}=0.001)$, HOMA-IR $(\mathrm{r}=0.46 ; \quad \mathrm{P}=0.001), \quad \mathrm{NT}$-pro-BNP $\quad(\mathrm{r}=0.42 ;$ $\mathrm{P}=0.001)$, LVEF ( $\mathrm{r}=0.37 ; \mathrm{P}=0.001)$, low-density lipoprotein cholesterol $(\mathrm{r}=0.32 ; \mathrm{P}=0.001)$, hs-CRP $(\mathrm{r}=0.31 ; \mathrm{P}=0.005)$, and TG $(\mathrm{r}=0.28$, $\mathrm{P}=0.001)$. The numerous of $\mathrm{CD} 31+/$ annexin $\mathrm{V}+\mathrm{EMPs}$ was directly

Table 1. General characteristic of patients participating in study.

\begin{tabular}{|c|c|c|c|c|}
\hline Parameters & Entire cohort patients $(n=300)$ & None IR subjects(n=129) & IR subjects $(n=171)$ & P value \\
\hline Age, years & $59.50 \pm 7.30$ & $57.90 \pm 8.10$ & $60.30 \pm 6.33$ & 0.26 \\
\hline Males, n (\%) & $186(62.0 \%)$ & $77(59.7 \%)$ & $109(63.7)$ & 0.23 \\
\hline Adherence to smoking, $\mathrm{n}(\%)$ & $66(22.0 \%)$ & $28(21.7 \%)$ & $38(22.2 \%)$ & 0.56 \\
\hline Hypertension, n (\%) & $184(61.3 \%)$ & $82(63.6 \%)$ & $102(59.6 \%)$ & 0.44 \\
\hline NYHA class I, n (\%) & $76(25.3 \%)$ & $34(26.4 \%)$ & $42(24.5 \%)$ & 0.62 \\
\hline NYHA class II, n (\%) & $74(24.7 \%)$ & $32(24.8 \%)$ & $42(24.6 \%)$ & 0.63 \\
\hline NYHA class III, $\mathrm{n}(\%)$ & $98(32.7 \%)$ & $45(34.9 \%)$ & $53(31.0 \%)$ & 0.60 \\
\hline NYHA class IV, n (\%) & $52(17.3 \%)$ & $18(13.9 \%)$ & $34(19.9 \%)$ & 0.12 \\
\hline Dyslipidemia, n (\%) & $143(47.7 \%)$ & $58(45.0 \%)$ & $85(49.7 \%)$ & 0.36 \\
\hline Obesity, n (\%) & $122(40.7 \%)$ & $44(34.1 \%)$ & $78(45.6 \%)$ & 0.042 \\
\hline BMI, $\mathrm{kg} / \mathrm{m}^{2}, \mathrm{M} ; 95 \% \mathrm{CI}$ & $24.2(22.0-27.9)$ & $23.07(22.3-25.7)$ & $25.99(23.5-28.6)$ & 0.054 \\
\hline GFR, $\mathrm{mL} / \mathrm{min} / 1.73 \mathrm{~m}^{2}, \mathrm{M} ; 95 \% \mathrm{CI}$ & $85.2(70.3-112.5)$ & $82.8(71.5-103.1)$ & $87.4(73.5-110.1)$ & 0.24 \\
\hline $\mathrm{HbA} 1 \mathrm{c}, \%, \mathrm{M} ; 95 \% \mathrm{CI}$ & $5.8(4.3-6.3)$ & $5.5(4.7-6.1)$ & $6.1(5.4-6.5)$ & 0.012 \\
\hline Fasting blood glucose, $\mathrm{mmol} / \mathrm{L}, \mathrm{M} ; 95 \% \mathrm{CI}$ & $5.10(3.4-6.1)$ & $4.97(4.87-5.07)$ & $5.47(5.14-6.0)$ & 0.001 \\
\hline Insulin, $\mu \mathrm{U} / \mathrm{mL}, \mathrm{M} ; 95 \% \mathrm{CI}$ & $13.12(12.22-14.01)$ & $10.41(9.92-10.91)$ & $15.15(13.69-16.62)$ & 0.016 \\
\hline Creatinine, $\mu \mathrm{mol} / \mathrm{L}, \mathrm{M} ; 95 \% \mathrm{CI}$ & $74.9(65.1-90.3)$ & $72.6(69.31-88.1)$ & $78.6(70.2-89.1)$ & 0.52 \\
\hline Total cholesterol, mmol/L, M; 95\% CI & $5.0(4.2-5.8)$ & $4.9(4.1-5.3)$ & $5.2(4.5-5.7)$ & 0.21 \\
\hline LDL-C, mmol/L, M; 95\% CI & $3.02(2.80-3.90)$ & $3.00(2.82-3.75)$ & $3.11(2.86-3.82)$ & 0.044 \\
\hline HDL-C, mmol/L, M; 95\% CI & $0.88(0.82-0.97)$ & $0.91(0.86-0.95)$ & $0.86(0.83-0.92)$ & 0.24 \\
\hline NT-pro-BNP, pg /mL, M; 95\% CI & $1533.6(644.5-2560.6)$ & $1066.9(910.3-1223.6)$ & $1480.5(1310.4-1650.7)$ & 0.001 \\
\hline hs-CRP, mg/L, M; 95\% CI & $7.34(6.77-7.95)$ & $7.11(6.38-7.84)$ & $7.51(6.68-8.33)$ & 0.016 \\
\hline Systolic BP, mm Hg, M \pm SD & $129 \pm 4$ & $131 \pm 6$ & $129 \pm 5$ & 0.52 \\
\hline Systolic BP, $\mathrm{mm} \mathrm{Hg}, \mathrm{M} \pm \mathrm{SD}$ & $77 \pm 5$ & $78 \pm 4$ & $77 \pm 6$ & 0.48 \\
\hline Heart rate, beats per $1 \mathrm{~min}, \mathrm{M} \pm \mathrm{SD}$ & $76 \pm 6$ & $75 \pm 4$ & $77 \pm 6$ & 0.54 \\
\hline LVEF, $\%, M \pm S D$ & $46.07 \pm 2.73$ & $48.62 \pm 1.64$ & $44.15 \pm 1.98$ & 0.02 \\
\hline
\end{tabular}

Note: Categorical variables are expressed as numerous (n) and percentages (\%).

Abbreviations: M: mean value, CI: confidence interval, BP: blood pressure, NYHA: New York Heart Association, T2DM: type two diabetes mellitus, GFR: glomerular filtration rate, HbA1c: glycated hemoglobin, HDL-C: high-density lipoprotein cholesterol, LDL-C: low-density lipoprotein cholesterol, BMI: body mass index, BNP: brain natriuretic peptide, LVEF: left ventricular ejection fraction. 
Berezin AE (2015) Interrelationship between insulin resistance and impaired immune phenotype of circulating endothelial-derived microparticles in none-diabetic patients with chronic heart failure

Table 2. Concomitant medications in CHF patients included in the study.

\begin{tabular}{|c|c|c|c|c|}
\hline Parameters & Entire cohort patients $(n=300)$ & None IR subjects(n=129) & IR subjects $(n=171)$ & P value \\
\hline ACEI or ARAs, $n(\%)$ & $300(100 \%)$ & $129(100 \%)$ & $171(100 \%)$ & 1.0 \\
\hline Mineralocorticoid receptor antagonists, $\mathrm{n}(\%)$ & $83(27.7 \%)$ & $33(25.6 \%)$ & $50(29.2 \%)$ & 0.14 \\
\hline Beta-blockers, n (\%) & $237(79.0 \%)$ & $88(68.21 \%)$ & $149(87.1)$ & 0.016 \\
\hline Acetylsalicylicacid, n (\%) & $278(92.7 \%)$ & $117(90.7 \%)$ & $161(94.2 \%)$ & 0.23 \\
\hline Other antiplatelet drugs, $\mathrm{n}(\%)$ & $22(7.3 \%)$ & $12(9.3 \%)$ & $10(5.8 \%)$ & 0.046 \\
\hline Ivabradine, $\mathrm{n}(\%)$ & $89(29.7 \%)$ & $26(20.2 \%)$ & $63(36.8 \%)$ & 0.026 \\
\hline Loop diuretics, $\mathrm{n}(\%)$ & $251(83.7 \%)$ & $109(84.5 \%)$ & $142(83.0 \%)$ & 0.48 \\
\hline Statins, n (\%) & $143(47.7 \%)$ & $58(45.0 \%)$ & $85(49.7 \%)$ & 0.36 \\
\hline
\end{tabular}

Abbreviations: IR: insulin resistance

Table 3. Immune phenotypes of EMPs in CHF patients.

\begin{tabular}{|l|c|c|c|c|}
\hline \multicolumn{1}{|c|}{ Immune phenotypes } & Entire cohort patients (n=300) & None IR subjects(n=129) & IR subjects (n=171) & P value \\
\hline CD144+/CD31+ EMPs, $n / m L$ & $0.91(0.36-1.35)$ & $0.90(0.34-1.27)$ & $0.93(0.41-1.32)$ \\
\hline CD144+/annexin V+ EMPs, $\mathrm{n} / \mathrm{mL}$ & $1.15(0.13-2.41)$ & $1.13(0.10-2.22)$ & $1.17(0.16-2.35)$ \\
\hline CD144+/CD31+/annexin V+ EMPs, n/mL & $1.01(0.39-1.70)$ & $0.98(0.35-1.53)$ & $1.05(0.44-1.63)$ \\
\hline CD31+/annexin V+ EMPs, $\mathrm{n} / \mathrm{mL}$ & $0.296(0.261-0.339)$ & $0.278(0.243-0.310)$ & $0.315(0.289-0.327)$ \\
\hline CD62E+ EMPs, $\mathrm{n} / \mathrm{mL}$ & $1.03(0.86-1.13)$ & $1.05(0.94-1.11)$ & 0.044 \\
\hline
\end{tabular}

Note: The values are presented as the median and $25-75 \%$ interquartile range, the differences validity values obtained by two-tailed Mann-Whitney test.

Abbreviations: IR: insulin resistance, EMPs: endothelial-derived microparticles.

Table 4. C-statistics for Models with HOMA-IR, NYHA class, hs-CRP, NT-proBNP as Continuous Variables.

\begin{tabular}{|c|c|c|c|c|c|c|c|c|}
\hline \multirow{2}{*}{ Models } & \multicolumn{4}{|c|}{ Dependent variable: CD144+/CD31+/annexin V+ EMPs } & \multicolumn{4}{|c|}{ Dependent variable: CD31+/annexin V+ EMPs } \\
\hline & AUC $(95 \%$ CI $)$ & $\Delta \mathbf{A U C}$ & IDI ( \pm SE) & Relative IDI (\%) & AUC $(95 \%$ CI) & $\Delta \mathbf{A U C}$ & IDI $( \pm$ SE) & Relative IDI (\%) \\
\hline $\begin{array}{l}\text { Model } 1 \text { (based model: HOMA-IR }> \\
2.77 \mathrm{mmol} / \mathrm{L} \times \mu \mathrm{U} / \mathrm{mL} \text { ) }\end{array}$ & 0.669 & - & - & - & 0.664 & - & - & - \\
\hline $\begin{array}{l}\text { Model } 1+\text { NYHA class + biomarkers } \\
\text { (hs-CRP, NT-proBNP) }\end{array}$ & 0.681 & - & - & - & 0.685 & - & - & - \\
\hline $\begin{array}{l}\text { Model } 1+\text { NYHA class + biomarkers } \\
\text { (hs-CRP, NT-proBNP) versus Model } 1\end{array}$ & - & $0.012 ; \mathrm{P}=0.64$ & $0.02 \pm 0.015$ & $1.8 \%$ & - & $0.021 ; \mathrm{P}=0.12$ & $0.03 \pm 0.012$ & $2.2 \%$ \\
\hline
\end{tabular}

Note: Relative IDI: calculated as the ratio of IDI over the discrimination slope of the model without IR.

Abbreviations: AUC: area under curve, SE: standard error, IR: insulin resistance, BNP: brain natriuretic peptide, hs-CRP: high sensitive C-reactive protein.

related with NYHA class $(\mathrm{r}=0.58 ; \mathrm{P}=0.001)$, HOMA-IR $(\mathrm{r}=0.462$, $\mathrm{P}=0.003)$, BMI $(\mathrm{r}=-0.38, \mathrm{P}=0.001)$, NT-proBNP $(\mathrm{r}=0.522, \mathrm{P}=0.001)$, hs-CRP ( $r=0.423, P=0.001)$, GFR $(r=-0.388, P=0.001)$, TG $(r=0.342$, $\mathrm{P}=0.001)$, creatinine $(\mathrm{r}=-0.362, \mathrm{P}=0.001)$, gender $(\mathrm{r}=0.318, \mathrm{P}<0.001$ for male), dyslipidemia $(r=0.313, P=0.001)$, age $(r=0.275, P=0.001)$, hypertension $(\mathrm{r}=0.23, \mathrm{P}=0.003)$, and smoking $(\mathrm{r}=0.212, \mathrm{P}=0.001)$.

Using the multivariate linear regression analysis we found that numerous of CD144+/CD31+/annexin V+ EMPs was associated with NYHA class $(\mathrm{r}=0.58 ; \mathrm{P}=0.001)$, HOMA-IR $(\mathrm{r}=0.44 ; \mathrm{P}=0.001)$, NTpro-BNP ( $\mathrm{r}=0.32 ; \mathrm{P}=0.001)$, LVEF $(\mathrm{r}=0.31 ; \mathrm{P}=0.001)$, hs-CRP $(\mathrm{r}=0.30$; $\mathrm{P}=0.005)$, and $\mathrm{TG}(\mathrm{r}=0.22, \mathrm{P}=0.001)$. Therefore, the numerous of $\mathrm{CD} 31+/$ annexin $\mathrm{V}+$ EMPs was associated with NYHA class $(\mathrm{r}=0.54$; $\mathrm{P}=0.001)$, HOMA-IR $(\mathrm{r}=0.45, \mathrm{P}=0.003), \mathrm{BMI}(\mathrm{r}=-0.32, \mathrm{P}=0.002)$, NTproBNP ( $\mathrm{r}=0.51, \mathrm{P}=0.001)$, hs-CRP $(\mathrm{r}=0.404, \mathrm{P}=0.003)$, TG $(\mathrm{r}=0.33$, $\mathrm{P}=0.001)$, and age $(\mathrm{r}=0.21, \mathrm{P}=0.001)$.

The multivariate logistic regression analyses identified independent predictors for elevation of apoptotic-derived EMPs labelled as CD144+/ $\mathrm{CD} 31+$ /annexin $\mathrm{V}+$ and $\mathrm{CD} 31+$ /annexin $\mathrm{V}+$ microparticles. HOMAIR $(\mathrm{OR}=1.14,95 \% \mathrm{CI}=1.08-1.21, \mathrm{P}=0.001)$, NT-proBNP $(\mathrm{OR}=1.07$, 95\% CI $=1.04-1.10, \mathrm{P}=0.001)$, hs-CRP $(\mathrm{OR}=1.04,95 \% \mathrm{CI}=1.02-1.07$, $\mathrm{P}=0.001)$, and NYHA class $(\mathrm{OR}=1.03,95 \% \mathrm{CI}=1.01-1.05, \mathrm{P}=0.001)$ predicted increased CD31+/annexin V+ EMPs. Therefore, HOMA-IR $(\mathrm{OR}=1.10,95 \% \mathrm{CI}=1.05-1.17, \mathrm{P}=0.001)$, NT-proBNP $(\mathrm{OR}=1.08,95 \%$ $\mathrm{CI}=1.04-1.12, \mathrm{P}=0.001)$, and NYHA class $(\mathrm{OR}=1.05,95 \% \mathrm{CI}=1.02$ -
$1.09, \mathrm{P}=0.001)$ significantly predicted elevation of $\mathrm{CD} 144+/ \mathrm{CD} 31+/$ annexin V+ EMPs.

Using C-statistics for Models with HOMA-IR, NYHA class, and circulating biomarkers (hs-CRP, NT-proBNP) as Continuous Variables we found that adding of these biomarkers (NYHA class, hs-CRP, and NT-proBNP) to the based model constructed with HOMA-IR did not improve the relative IDI for increased CD144+/CD31+/annexin V+ and CD31+/annexin V+ microparticles (Table 4).

When we used other model constructed on entering variables, IDI avoids to be improved for increased CD144+/CD31+/annexin V+ and CD31+/annexin V+ microparticles (available for NYHA class and circulating hs-CRP and NT-proBNP as continuous variables) (Table 5). Thus, we found that IR remained a statistically significant predictor for increased apoptotic EMPs labelled as CD144+/CD31+/annexin V+ and CD31+/annexin V+ EMPs in none-diabetic patients with CHF patients and that these findings reflect exiting impaired phenotype of circulating EMPs in this patient population.

\section{Discussion}

The results of our investigations shown that IR in nonediabetic population of CHF patients may consider a predictor of impaired phenotype of circulating EMPs, which reflects surpass of apoptotic-derived microparticles in circulation association with probably relatively deficiency of activated endothelial cell-derived 
Berezin AE (2015) Interrelationship between insulin resistance and impaired immune phenotype of circulating endothelial-derived microparticles in none-diabetic patients with chronic heart failure

Table 5. Prediction Performance Analyses for Models with HOMA-IR NYHA class, hs-CRP, NT-proBNP as Continuous Variables for increased CD144+/CD31+/annexin V+ and CD31+/ annexin $\mathrm{V}+$ EMPs.

\begin{tabular}{|l|c|c|}
\hline Model 2 vs Model 1 & Dependent variable: CD144+/CD31+/annexin V+ EMPs & Dependent variable: CD31+/annexin V+ EMPs \\
\hline Categorical NRI & $0.11(95 \% \mathrm{CI}=0.07-0.16)$ & $0.08(95 \% \mathrm{CI}=0.06-0.11)$ \\
\hline Percentage of events correctly reclassified & $3(\mathrm{p}=0.64)$ & $2(\mathrm{p}=0.72)$ \\
\hline Percentage of non-events correctly reclassified & $4(\mathrm{p}=0.26)$ & $2(\mathrm{p}=0.81)$ \\
\hline Categorical free NRI & $0.13(95 \% \mathrm{CI}=0.09-0.15)$ & $0.11(95 \% \mathrm{CI}=0.06-0.14)$ \\
\hline Percentage of events correctly reclassified & $2 \%(\mathrm{p}=0.44)$ & $1 \%(\mathrm{p}=0.88)$ \\
\hline Percentage of non-events correctly reclassified & $4 \%(\mathrm{p}=0.48)$ & $4 \%(\mathrm{p}=0.62)$ \\
\hline
\end{tabular}

Note: Model 1-HOMA-IR $>2.77 \mathrm{mmol} / \mathrm{L} \times \mu \mathrm{U} / \mathrm{mL}$; Model 2-NYHA class, hs-CRP, NT-proBNP.

Abbreviations: NRI: net reclassification improvement, IR: insulin resistance, BNP: brain natriuretic peptide, hs-CRP: high sensitive C-reactive protein.

microparticles. Recent studies shown that IR may frequently associate with CHF $[37,38]$ and even it is able appeared to be prior to clinical manifestation of CHF $[39,40]$. In fact, we did not know whether impaired phenotype of circulating EMPs appears to be prior IR or after dysmetabolic disorders. However, IR emerges at early stage of $\mathrm{CHF}$ and probably it associates with other cardiovascular risk factors [41]. Contrary to expectation, no independent association has been verified between the circulating EMPs and such cardiovascular risk factors as smoking, obesity and hypertension. However, the causality relation IR with impaired immune phenotype in none-diabetic CHF patients is required detail explanation, while the innate exact molecular mechanisms affected abovementioned phenomenon is still under recognized. Probably, oxidative stress and inflammation may elicit or exacerbate IR in CHF subjects [42,43], although our results did not confirm independent causality role of these mechanisms in impaired phenotype of EMPs. We suggested that IR affects wide spectrum cells including endothelial cells, which avoid being able to secret proangiogenic microparticles. Therefore, IR did not allow endothelial cells to be resistant to inflammatory stimuli and direct injury. All these processes may lead to increased apoptotic-derived EMPs that are able to mediate endothelial inflammation and decrease ability to endothelial repair. Thus, impaired apoptotic phenotype in CHF patients reflects a limiting capacity of endothelial cell to maintain cardiac function in the face of co-morbidities such as IR. Whether these findings are predictable for none-diabetic patients with CHF is not obviously understood. Moreover, it is not clear whether serial measurements of circulating EMPs are considered a diagnostic tool for risk stratification of the patients with CHF. More studies are underway to evaluate the role of IR in impaired phenotype of circulating EMPs among $\mathrm{CHF}$ subjects.

\section{Conclusion}

We found that IR remained a statistically significant predictor for increased apoptotic-derived EMPs labelled as CD144+/CD31+/ annexin $\mathrm{V}+$ and $\mathrm{CD} 31+/$ annexin $\mathrm{V}+\mathrm{EMPs}$ in none-diabetic patients with CHF.

\section{Limitations of the study}

This study has some restrictions. First our study is limited by its retrospective nature and small sample size. The authors believe that a greater cohort is to be desirable to improve the power of the study. Therefore, there were several technical-related difficulties in the measurement of EMPs. In fact, lack of standard protocol for isolating and detecting circulating EMPs obtained from the plasma. According opinion of the majority experts, centrifugation is became the main factor mediated reliability of the EMP determination in samples and contributed in biological variability of EMP count. Although HDFACS methodology is widely used, theoretically overlap between two or more fluorochromes might reflect some obstacles for further interpretation of obtained results. Another limitation of the present study is that a specific role of EMPs is also possible and has not been characterized in depth in T2DM patients. However, the authors suppose that these restrictions might have no significant impact on the study data interpretation. Additionally, retrospective, relative small sample size may limit the significance of the present study. However, this was not a randomized and controlled study. The authors believe that a greater cohort of patients with more incidences detected is desirable to improve the credibility of the study.

\section{Acknowledgement}

We thank all patients for their participation in the investigation, staff of the Regional Zaporozhye Hospital (Ukraine) and the doctors, nurses, and administrative staff in City hospital \# 6 (Zaporozhye, Ukraine), general practices, and site-managed organizations that assisted with the study.

\section{Ethical principles}

All the patients have given their written informed consent for participation in the study. The investigators followed strictly all the requirements to clinical trials in conformity with the World Medical Association Declaration of Helsinki, 1964, Good Clinical Practice proveided by International Conference on Harmonization, Council of Europe Conventionfor theProtectionof Human Rights and Dignityofthe Human Being in view of using achievements in biology and medicine, Convention on Human Rights and Biomedicine, including Additional Protocol to the Conventionon Human Rights and Biomedicine,concer ningBiomedical Research, and legislation of Ukraine.

\section{Authors' contributions}

Alexander E Berezin initiated the hypothesis and designed the study protocol, contributed to collect, analyze and interpret the data, performed statistical analysis, and wrote the manuscript. Alexander A. Kremzer contributed to enroll the patients, collected and analyzed the data, checked clinical events and reviewed the source documents. Yulia V. Martovitskaya contributed circulating biomarker determination, preformed preparation of isolates of microparticles in samples with further phenotyping by flowcytometry, and interpreted the obtained results. Tatyana A. Samura preformed visualization procedures and analyzed the results of examinations. Tatyana A. Berezina contributed to enroll the patients in the study and collect the data.

\section{References}

1. Redfield MM, Jacobsen SJ, Burnett JC Jr, Mahoney DW, Bailey KR, et al. (2003) Burden of systolic and diastolic ventricular dysfunction in the community: appreciating the scope of the heart failure epidemic. JAMA 289: 194-202. [Crossref]

2. Goldberg RJ, Spencer FA, Farmer C, Meyer TE, Pezzella S (2005) Incidence and 
Berezin AE (2015) Interrelationship between insulin resistance and impaired immune phenotype of circulating endothelial-derived microparticles in none-diabetic patients with chronic heart failure

hospital death rates associated with heart failure: a community-wide perspective. $A m J$ Med 118: 728-734. [Crossref]

3. Baliga V, Sapsford R (2009) Review article: Diabetes mellitus and heart failure--an overview of epidemiology and management. Diab Vasc Dis Res 6: 164-171. [Crossref]

4. Bastien M, Poirier P, Lemieux I, Després JP3 (2014) Overview of epidemiology and contribution of obesity to cardiovascular disease. Prog Cardiovasc Dis 56: 369-381. [Crossref]

5. MacDonald MR, Petrie MC, Hawkins NM, Petrie JR, Fisher M, et al. (2008) Diabetes, left ventricular systolic dysfunction, and chronic heart failure. Eur Heart J 29: 12241240. [Crossref]

6. Chinali M, Joffe SW, Aurigemma GP, Makam R, Meyer TE, et al. (2010) Risk factors and comorbidities in a community-wide sample of patients hospitalized with acute systolic or diastolic heart failure: the Worcester Heart Failure Study. Coron Artery Dis 21: 137-143. [Crossref]

7. Helfand BK, Maselli NJ, Lessard DM, Yarzebski J, Gore JM, et al. (2014) Elevated serum glucose levels and survival after acute heart failure: A population-based perspective. Diab Vasc Dis Res 12: 119-125. [Crossref]

8. Shah AD, Langenberg C, Rapsomaniki E, Denaxas S, Pujades-Rodriguez M, et al (2015) Type 2 diabetes and incidence of cardiovascular diseases: a cohort study in 1.9 million people. Lancet Diabetes Endocrinol 3: 105-113. [Crossref]

9. Ingelsson E, Sundström J, Arnlöv J, Zethelius B, Lind L (2005) Insulin resistance and risk of congestive heart failure. JAMA 294: 334-341. [Crossref]

10. Ingelsson E, Arnlöv J, Sundström J, Zethelius B, Vessby B, et al. (2005) Nove metabolic risk factors for heart failure. J Am Coll Cardiol 46: 2054-2060. [Crossref]

11. Tsutsui H, Kinugawa S, Matsushima S (2011) Oxidative stress and heart failure. Am J Physiol Heart Circ Physiol 301: H2181-2190. [Crossref]

12. Oka T, Akazawa H, Naito AT, Komuro I (2014) Angiogenesis and cardiac hypertrophy: maintenance of cardiac function and causative roles in heart failure. Circ Res 114: 565 571. [Crossref]

13. Shimizu I, Yoshida Y, Katsuno T, Minamino T (2013) Adipose tissue inflammation in diabetes and heart failure. Microbes Infect 15: 11-17. [Crossref]

14. Tuunanen H, Engblom E, Naum A, Scheinin M, Någren K, et al (2006) Decreased myocardial free fatty acid uptake in patients with idiopathic dilated cardiomyopathy: evidence of relationship with insulin resistance and left ventricular dysfunction. J Card Fail 12: 644-652. [Crossref]

15. Shimizu I, Yoshida Y, Katsuno T, Tateno K, Okada S, et al. (2012) p53-induced adipose tissue inflammation is critically involved in the development of insulin resistance in heart failure. Cell Metab 15: 51-64. [Crossref]

16. Arnlöv J, Lind L, Zethelius B, Andrean B, Hales CN, et al. (2001) Several factors associated with the insulin resistance syndrome are predictors of left ventricular systolic dysfunction in a male population after 20 years of follow-up. Am. Heart $J 142$ : 720-724. [Crossref]

17. Berezin AE, Kremzer AA, Samura TA, Martovitskaya YV (2014) Circulating endothelial-derived apoptotic microparticles in the patients with ischemic symptomatic chronic heart failure: relevance of pro-inflammatory activation and outcomes. Int Cardiovasc Res J 8: 116-123. [Crossref]

18. Berezin AE, Kremzer AA, Samura TA, Martovitskaya YV, Malinovskiy YV, et al (2014) Predictive value of apoptotic microparticles to mononuclear progenitor cells ratio in advanced chronic heart failure patients. J Cardiol 7: S0914-5087. [Crossref]

19. Shah KB, Kontos MC2 (2014) Microparticles and left ventricular assist device complications: a causal association? J Heart Lung Transplant 33: 468-469. [Crossref]

20. Nozaki T, Sugiyama S, Sugamura K, Ohba K, Matsuzawa Y, et al. (2010) Prognostic value of endothelial microparticles in patients with heart failure. Eur J Heart Fail 12: 1223-1228. [Crossref]

21. Barteneva NS, Fasler-Kan E, Bernimoulin M, Stern JN, Ponomarev ED, et al. (2013) Circulating microparticles: square the circle. BMC Cell Biol 14: 23. [Crossref]

22. Guay C, Regazzi R (2015) Role of islet microRNAs in diabetes: which model for which question? Diabetologia 58: 456-463. [Crossref]
23. Wu ZH, Ji CL, Li H, Qiu GX, Gao CJ, et al. (2013) Membrane microparticles and diseases. Eur Rev Med Pharmacol Sci 17: 2420-2427. [Crossref]

24. Tetta C, Bruno S, Fonsato V, Deregibus MC, Camussi G (2011) The role of microvesicles in tissue repair. Organogenesis 7: 105-115. [Crossref]

25. Martinez MC, Andriantsitohaina R (2011) Microparticles in angiogenesis: therapeutic potential. Circ Res 109: 110-119. [Crossref]

26. Rautou PE, Vion AC, Amabile N, Chironi G, Simon A, et al. (2011) Microparticles, vascular function, and atherothrombosis. Circ Res 109: 593-606. [Crossref]

27. Kurtzman N, Zhang L, French B, Jonas R, Bantly A, et al. (2013) Personalized cytomic assessment of vascular health: Evaluation of the vascular health profile in diabetes mellitus. Cytometry B Clin Cytom 84: 255-266. [Crossref]

28. Lim MJ, White CJ (2013) Coronary angiography is the gold standard for patients with significant left ventricular dysfunction. Prog Cardiovasc Dis 55: 504-508. [Crossref]

29. Lang RM, Badano LP, Mor-Avi V, Afilalo J, Armstrong A, et al. (2015) Recommendations for cardiac chamber quantification by echocardiography in adults: an update from the American society of echocardiography and the European association of cardiovascular imaging. J Am Soc Echocardiogr 28: 1-39.

30. Pellerin D, Sharma R, Elliott P, Veyrat C (2003) Tissue Doppler, strain, and strain rate echocardiography for the assessment of left and right systolic ventricular function. Heart 89 Suppl 3: iii9-17. [Crossref]

31. Matthews DR, Hosker JP, Rudenski AS, Naylor BA, Treacher DF, et al. (1985) Homeostasis model assessment: insulin resistance and beta-cell function from fasting plasma glucose and insulin concentrations in man. Diabetologia 28: 412-419. [Crossref]

32. Levey AS, Stevens LA, Schmid CH, Zhang YL, Castro AF 3rd, et al. (2009) A new equation to estimate glomerular filtration rate. Ann Intern Med 150: 604-612. [Crossref]

33. Friedewald WT, Levy RI, Fredrickson DS (1972) Estimation of the concentration of low-density lipoprotein cholesterol in plasma, without use of the preparative ultracentrifuge. Clin Chem 18: 499-502. [Crossref]

34. Orozco AF, Lewis DE (2010) Flow cytometric analysis of circulating microparticles in plasma. Cytometry A 77: 502-514. [Crossref]

35. Lacroix R, Judicone C, Mooberry M, Boucekine M, Key NS, et al. (2013) The ISTH SSC Workshop. Standardization of pre-analytical variables in plasma microparticle determination: results of the International Society on Thrombosis and Haemostasis SSC Collaborative workshop. J Thromb Haemost [Epub ahead of print]. [Crossref]

36. Tung JW, Parks DR, Moore WA, Herzenberg LA, Herzenberg LA (2004) New approaches to fluorescence compensation and visualization of FACS data. Clin Immunol 110: 277-283. [Crossref]

37. McGuire DK, Gore MO2 (2013) Insulin resistance and risk for incident heart failure. JACC Heart Fail 1: 537-539. [Crossref]

38. Kosmala W, Jellis CL, Marwick TH (2014) Exercise Limitation Associated With Asymptomatic Left Ventricular Impairment: Analogy with Stage B Heart Failure. J Am Coll Cardiol 65: 257-266. [Crossref]

39. Giuseppina N, Marinella P, Claudia V, Pietro S, Marianna F, et al. (2014) Early subclinical ventricular dysfunction in patients with insulin resistance. $J$ Cardiovasc Med (Hagerstown) 15: 110-114. [Crossref]

40. Vardeny O, Gupta DK, Claggett B, Burke S, Shah A, et al. (2013) Insulin resistance and incident heart failure the ARIC study (Atherosclerosis Risk in Communities). JACC Heart Fail 1: 531-536. [Crossref]

41. Gouya G, Voithofer P, Neuhold S, Storka A, Vila G, et al. (2014) Association of nutritional risk index with metabolic biomarkers, appetite-regulatory hormones and inflammatory biomarkers and outcome in patients with chronic heart failure. Int J Clin Pract 68: 1293-1300. [Crossref]

42. Doehner W, Frenneaux M, Anker SD3 (2014) Metabolic impairment in heart failure: the myocardial and systemic perspective. J Am Coll Cardiol 64: 1388-1400. [Crossref]

43. Carvajal K, Balderas-Villalobos J, Bello-Sanchez MD, Phillips-Farfán B, MolinaMuñoz T, et al. (2014) $\mathrm{Ca}(2+)$ mishandling and cardiac dysfunction in obesity and insulin resistance: role of oxidative stress. Cell Calcium 56: 408-415. [Crossref]

Copyright: (C2015 Berezin AE. This is an open-access article distributed under the terms of the Creative Commons Attribution License, which permits unrestricted use, distribution, and reproduction in any medium, provided the original author and source are credited. 